\title{
Reflections on a Case of Psoriasis in the Simien Mountains of Ethiopia
}

Isabella De Vere Hunt ${ }^{*}$

Medical Sciences Division, University of Oxford, Oxford, UK

*Corresponding author: Hunt IDV, Medical Sciences Division, University of Oxford, Oxford, UK, Tel: +44 1865 270000; E-mail: isabella.deverehunt@balliol.ox.ac.uk Received date: May 10, 2018; Accepted date: July 06, 2018; Published date: July 10, 2018

Copyright: @2018 Hunt IDV. This is an open-access article distributed under the terms of the Creative Commons Attribution License, which permits unrestricted use, distribution, and reproduction in any medium, provided the original author and source are credited.

\begin{abstract}
This report addresses the case of a 15-year-old boy with extensive plaque psoriasis seen by an outreach nurse in Northern Ethiopia. It addresses firstly the issue of misdiagnosis, but moves on to focus on the considerable psychological burden that chronic skin disease imparts. The case is a poignant reminder that healthcare practitioners must always consider the psychosocial implications of a condition that is perceived as disfiguring by the patient.
\end{abstract}

Keywords: Psoriasis; Psychological; Stigmatised

\section{Introduction}

During an elective placement in the Simien Mountains of Northern Ethiopia, I encountered a 15-year-old boy with extensive plaque psoriasis. He was seen in an outreach clinic conducted by a 'mobile nurse' who visits various remote settlements in the region.

\section{Case Report}

During an elective placement in the Simien Mountains of Northern Ethiopia, I encountered a 15-year-old boy with extensive plaque psoriasis. He was seen in an outreach clinic conducted by a 'mobile nurse' who visits various remote settlements in the region. She had first encountered him 3 years ago, and treated him for presumed scabies for several months with a sulphur-based cream. She attributed the failure of treatment response to non-compliance with medication. The complaint that he re-presented with to us was conspicuous plaques on his cheek and in the pre-auricular region; however, on head-to-toe skin examination, extensive psoriasis on all four limbs and torso was also revealed. The nurse had not previously looked for further areas of disease beyond what was shown on the boy's face, and indeed had not heard of the condition 'psoriasis'.

With the nurse acting as a translator, a very limited history was taken in which I established that there was no family history of psoriasis that the patient was aware of, and that he could not determine a trigger for the start of his skin condition or even be sure exactly when it came on. He did not have associated nail changes or report joint pains. Although tobacco smoking is practically nonexistent in this rural farming community, nearly everyone lives and sleeps in a house with a continuously burning open fire and thus smoke exposure in this regard can be presumed.

As I was unable to communicate directly with the patient, I first explained the condition to the nurse, and answered her questions about treatment options. I suggested topical treatments as a first measure, taking in to account the considerable resource-limitations. She seemed surprised that this was not an infectious condition but rather a chronic disease, and ended the consultation with the patient rather abruptly. I asked for an explanation of what she had translated to the patient, and she replied that she had reassured him it was 'just a cosmetic problem' and not infectious, and sent him on his way without any discussion of treatment.

\section{Reflections}

The considerable impact of dermatological problems on adolescent psychological health is well documented in the developed world [1]. However, there is little comparable research in developing countries, in which research efforts are unsurprisingly largely directed towards 'mortality' over 'morbidity'.

I felt very powerless in a situation in which the huge gulf in our healthcare expectations and assumptions was so acutely demonstrated. Of course it is important to hold caution with our judgements in a setting so far removed from our own, and it was clear that the nurse thought the diagnosis of 'psoriasis' was positive news. However, the look of disappointment on the patient's face when he was sent away with no treatment transcended all language barriers, and reinforced my feeling that despite the failure of the nurse to understand why this was a serious condition, the boy himself felt it all too keenly.

In the developed world, few healthcare professionals would overlook the wealth of long-standing evidence demonstrating the considerable disability provoked by psoriasis [2]. Furthermore, more recently, there has been a growing body of evidence suggesting increased mortality rates due to a higher prevalence of cardiovascular risk factors in this patient group [3]. However, in the case of this young boy, it was his psychological wellbeing that concerned me most, with this aspect of his care not even acknowledged, let alone addressed. With a conspicuous facial rash that he could not conceal, in a community which did not understand the condition but assumed him to have a contagious skin infestation, one can only imagine how isolated he must feel.

However, can we not all learn from this hyperbolic example of the failure of a healthcare practitioner to realise the tremendous psychological burden that chronic skin disease can impart, particularly on adolescents? Can we use it as a reminder of how misinterpreted and stigmatised skin rashes can be in the wider community, even in populations with better health education? Indeed, in the UK, it is not uncommon for patients to be mortified by their rashes (even inconspicuous ones) due to fears of what people 'might think'. Of course it is good news when a skin condition is neither imminently 
life-threatening nor highly contagious, but we must never overlook the psychosocial implications of a condition that is perceived as disfiguring by the patient.

\section{Discussion and Conclusion}

I hope that we can all learn from this hyperbolic example of the failure of a healthcare practitioner to realise the tremendous psychological burden that chronic skin disease can impart, particularly on adolescents. It is a poignant reminder of how misinterpreted and stigmatised skin rashes can be in the wider community, and is relevant even in populations with better health education. Indeed, in the UK, it is not uncommon for patients to be mortified by their rashes (even inconspicuous ones) due to fears of what people 'might think'. Of course it is good news when a skin condition is neither imminently life-threatening nor highly contagious, but we must never overlook the psychosocial implications of a condition that is perceived as disfiguring by the patient.

\section{References}

1. Golics CJ, Basra MKA, Finlay AY, Salek MS (2009) Adolescents with skin disease have specific quality of life issues. Dermatol Basel Switz 218: 357366.

2. Rapp SR, Feldman SR, Exum ML, Fleischer AB, Reboussin DM (1999) Psoriasis causes as much disability as other major medical diseases. J Am Acad Dermatol 41: 401-407.

3. Horreau C, Pouplard C, Brenaut E, Barnetche T, Misery L, et al. Cardiovascular morbidity and mortality in psoriasis and psoriatic arthritis: A systematic literature review. J Eur Acad Dermatol Venereol 27: $12-29$ 